CASE REPORT

\title{
Bilateral diaphragmatic paralysis and related respiratory complications in a patient with West Nile virus infection
}

\author{
A D Betensley, S H Jaffery, H Collins, N Sripathi, F Alabi
}

Thorax 2004;59:268-269. doi: 10.1136/thx.2003.9092

The case report is presented of a patient with West Nile virus infection and ventilator dependent respiratory failure in whom bilateral diaphragmatic paralysis developed. If the prevalence of West Nile virus infection continues to rise, recognition of diaphragmatic paralysis and related respiratory complications will become increasingly important to the pulmonary/critical care physician.

$\mathrm{W}$ est Nile virus (WNV) is a mosquito borne flavivirus that primarily infects birds but occasionally infects humans. Since the first case reports in the US in 1999, the frequency of WNV outbreaks in humans has increased with a total of almost 4000 cases being reported. Over 500 cases were reported in the state of Michigan in 2002; 32 cases were diagnosed at the Henry Ford Hospital, five of which required mechanical ventilation. In one patient respiratory failure persisted and diaphragmatic paralysis was eventually diagnosed.

\section{CASE REPORT}

A 54 year old man presented with fever, altered mental status, and seizure. He had a history of alcohol and tobacco abuse but no other previous illnesses, and he was not taking any medications. After emergency intubation, examination revealed normal breath sounds and right upper extremity paralysis. The chest radiograph and brain CT scan were normal. The cerebrospinal fluid (CSF) contained 180 white blood cells $/ \mathrm{mm}^{3}$ with $39 \%$ neutrophils, 55\% lymphocytes, a glucose level of $103 \mathrm{mg} / \mathrm{dl}$, and a protein level of $81 \mathrm{mg} / \mathrm{dl}$. The CSF immunoglobulin M (IgM) for WNV was positive. Other laboratory studies were unrevealing.
On day 7 the patient showed significant clinical improvement and his mental status returned to normal, but he still remained ventilator dependent. On days 14 and 75 electrodiagnostic studies were performed (table 1). Initially they revealed reduced motor responses and preserved sensory responses with denervation potentials (positive sharp waves, fibrillation potentials, and fasciculation potentials) and decreased recruitment of motor units, consistent with the involvement of either motor axons or anterior horn cells. The sensory abnormalities that developed over the course of his illness may have reflected an additional component of critical illness neuropathy.

By day 37 the patient was clinically stable but he had persistent thick respiratory secretions and the chest radiograph showed left lower lobe atelectasis. Despite bronchoscopy, atelectasis persisted and nebulised 3\% saline was administered every 4 hours with a resulting subjective reduction in the viscosity of the secretions. Theophylline was started on day 51 potentially to improve diaphragmatic strength.

Throughout the course of the illness the patient experienced occasional fevers with associated purulent respiratory secretions. Cultures of tracheal aspirates consistently grew Pseudomonas aeruginosa despite multiple courses of appropriate intravenous antibiotics. On day 67 nebulised colistimethate sodium (Coly-Mycin M Parenteral; Monarch Pharmaceuticals, Bristol, TN, USA) $150 \mathrm{mg}$ twice daily was started. The fevers subsided soon thereafter and subsequent respiratory cultures failed to grow Pseudomonas.

During his stay in hospital the patient remained ventilator dependent and a tracheostomy was performed on day 16 . Objective measures of respiratory muscle strength were consistently reduced with a negative inspiratory pressure of $-10 \mathrm{~cm} \mathrm{H}_{2} \mathrm{O}$ on day 5 and $-8 \mathrm{~cm} \mathrm{H}_{2} \mathrm{O}$ on day 80. Phrenic nerve conduction studies were performed on day 109 .

Table 1 Summary of electrodiagnostic studies

\begin{tabular}{lll}
\hline & Day 14 & Day 75 \\
\hline Nerve & & \\
Median sensory (wrist) $(>25 \mu \mathrm{V} /<2.8 \mathrm{~ms})$ & Right $(14.6 \mu \mathrm{V} / 4.4 \mathrm{~ms})$ & Right $(3.0 \mu \mathrm{V} / 4.4 \mathrm{~ms})$ \\
Radial sensory (wrist) $(>10 \mu \mathrm{V} /<2.7 \mathrm{~ms})$ & Right $(15.6 \mu \mathrm{V} / 3.1 \mathrm{~ms})$ & Not performed \\
Median motor (wrist) $(>4 \mathrm{mV} /<4.5 \mathrm{~ms})$ & Right $(0.9 \mathrm{mV} / 4.6 \mathrm{~ms})$ & Right $(0.7 \mathrm{mV} / 4.8 \mathrm{~ms})$ \\
Median motor (elbow) (not applicable) & Right $(0.8 \mathrm{mV} / 11.7 \mathrm{~ms})$ & Right $(0.6 \mathrm{mV} / 12.3 \mathrm{~ms})$ \\
Ulnar motor (wrist) $(>6 \mathrm{mV} /<3.5 \mathrm{~ms})$ & Right $(1.9 \mathrm{mV} / 3.3 \mathrm{~ms})$ & Absent response \\
Ulnar motor (elbow) (not applicable) & Right $(1.8 \mathrm{mV} / 10.5 \mathrm{~ms})$ & Not performed \\
Musclet & Right (inc $/ 1+/ \mathrm{dec})$ & Right (inc $/ 3+/ \mathrm{dec})$ \\
FDI & Right (inc $/ 2+/ \mathrm{dec})$ & Right (inc $/ 3+/ \mathrm{dec})$ \\
Bicieps brachii & Right (inc $/ 1+/ \mathrm{dec})$ & Right (inc $/ 2+/ \mathrm{dec})$ \\
Tibialis anterior & Right (inc $/ 0 / \mathrm{dec})$ & Not performed \\
Vastus medialis & & \\
\hline
\end{tabular}

$\mathrm{FDI}=$ first dorsal interosseus; inc $=$ increased; $\mathrm{dec}=$ decreased.

*Normal values for amplitude and latency are shown in parentheses for each nerve.

tInsertional activity/fibrillation potentials/motor unit recruitment are shown in parentheses for each muscle. Fibrillation potentials are recorded as 0 if not present and on a $1+$ to $4+$ scale if present. 
Bilateral transcutaneous electrical stimulation of the phrenic nerve with surface recordings of diaphragmatic activity failed to elicit a motor action potential on either side, suggesting bilateral diaphragmatic paralysis. On day 112 the patient still required full mechanical ventilatory support and was discharged to a long term facility.

\section{DISCUSSION}

Approximately one of $100 \mathrm{WNV}$ infections in humans results in clinical disease. ${ }^{2}$ In the New York outbreak of 1999, 27\% of patients showed signs of muscle weakness, $10 \%$ had flaccid paresis, $32 \%$ had respiratory symptoms, and $17 \%$ required mechanical ventilation. ${ }^{2}$ Previously published case series do not expand on the reason for mechanical ventilation. In our review of the literature this is the first report to identify bilateral diaphragmatic paralysis in a patient with WNV infection and ventilator dependent respiratory failure.

When presented with neuromuscular disease in a critically ill patient a number of contributing factors must be considered including electrolyte disturbances, poor nutrition, or medications such as neuromuscular blockers, corticosteroids, and aminoglycosides. We were able to maintain adequate nutrition and electrolyte balance in our patient, he did not receive neuromuscular blocking agents, but he did receive corticosteroids and aminoglycoside antibiotics. Although we cannot rule out a contribution from these agents, the phrenic nerve conduction study was performed more than 30 days after the last dose of corticosteroid or aminoglycoside. The persistence of inspiratory muscle weakness after discontinuation of these agents makes their contribution unlikely.

In general, treatment of patients with WNV infection is mainly supportive care, although immunoglobulin containing anti-WNV antibodies have been used successfully in immunocompromised patients with WNV encephalitis. ${ }^{3}$ Theophylline can potentially increase diaphragmatic strength, and recent animal studies have shown improvement in diaphragmatic strength with theophylline after spinal cord hemisection. ${ }^{4}$ Bronchial mucus hypersecretion has been described in patients with spinal cord injury due to inhibition of peripheral sympathetic stimulation, ${ }^{5}$ and the copious thick sputum production in our patient may have been produced via a similar mechanism.

Previous reports have neglected to discuss the respiratory complications associated with WNV infection. Although mucus hypersecretion and Pseudomonas infection may occur simply with prolonged mechanical ventilation, they contributed to morbidity in this patient and should be considered as potential complications of WNV infection. If the prevalence of WNV continues to increase in the future, recognition of diaphragmatic paralysis and related respiratory complications will become increasingly important to the pulmonary/critical care physician.

\section{Authors' affiliations}

A D Betensley, S H Jaffery, H Collins, F Alabi, Department of Internal Medicine, Pulmonary/Critical Care Division, Henry Ford Hospital,

Detroit, Michigan, USA

N Sripathi, Department of Neurology, Henry Ford Hospital, Detroit, Michigan, USA

No financial support was obtained.

Correspondence to: $\operatorname{Dr}$ A D Betensley, Department of Internal Medicine, Pulmonary/Critical Care Division, Henry Ford Hospital, 2799 W Grand Blvd, Detroit, Michigan 48202, USA; abetens1@hfhs.org

Received 21 April 2003

Accepted 22 June 2003

\section{REFERENCES}

1 CDC Office of Communication Media Relations. www.cdc.gov/od/oc/ media/wncount.htm (accessed 31 December 2002).

2 Nash D, Mostashari F, Fine A, et al. The outbreak of West Nile virus infection in the New York City area in 1999. N Engl J Med 2001;344:1807-14.

3 Hamdan AP, Green P, Mendelson E, et al. Possible benefit of intravenous immunoglobulin therapy in a lung transplant recipient with West Nile virus encephalitis. Transpl Infect Dis 2002;4:160-2.

4 Nantwi KD, Goshgarian HG. Theophylline-induced recovery in a hemidiaphragm paralyzed by hemisection in rats: contribution of adenosine receptors. Neuropharmacology 1998;37:113-21.

5 Bhaskar KR, Brown R, O'Sullivan DD, et al. Bronchial mucus hypersecretion in acute quadriplegia. Macromolecular yields and glycoconjugate composition. Am Rev Respir Dis 1991;143:640-8. 